\title{
Factors Affecting Women's Participation in the Jordanian Workforce
}

\author{
Salime Mehtap, Yazan Jayyousi, Njood Gammoh, and Ahmad Al Haj
}

\begin{abstract}
Women's participation in the workforce contributes to economic development, empowerment, gender equality and helps to uplift society. Yet the number of women who are active in the global workforce is still low, particularly in the Middle East and this has been attributed to a number of socio-economic reasons. This exploratory study aims to compile a profile of the non-working Jordanian female and gauge their perceptions of certain socio-economic factors that affect female participation in the labor force. It also attempts to measure their degree of satisfaction with staying at home. Out of the 145 non-working women surveyed, the majority were married with children, a university graduate without any work experience and with a household income of over 1,000 JOD. In general these women acknowledged that there were socio-economic factors deterring them from engaging in the work force and if they were to work it would be for reasons of self-actualization and preferably within the public sector. Except for education level and family income there were no significant differences in perceptions with respect to certain demographic factors. Respondents believe that gender stereotypes should not be an obstacle to working and are against men being given preferential treatment for positions. Sometimes their perceptions did not reflect actual reality and many respondents were not really aware of women friendly labor laws. Finally, the majority of women were not satisfied with staying at home. The results of this study calls for concrete action to amend labor laws, and help break down gender stereotypes and cultural taboos within Jordanian society. Women's participation in the labor force is imperative for the economic development of the country.
\end{abstract}

Index Terms-Economic development, employment, Jordan, women, workforce participation.

\section{INTRODUCTION}

Women constitute around 40 percent of the global formal labor force [1], [2]. According to [3], countries with high participation rates of women in the labor force, have a greater contribution to economic development. While much progress has been made in getting more women into the workforce [4], many challenges remain such as fewer employment opportunities, gender inequality, social and cultural obstacles, discriminatory work practices and lower salaries [5]-[8]. In addition, certain demographic features such as age, marital status, religion, the level of education, income, area of residence and spousal support can also affect women's participation in the labor force [9]-[13].

The existing status quo in the Arab world is currently being challenged with many countries going through political and social turmoil. Citizens are demanding

Manuscript received May 30, 2015; revised August 18, 2015.

The authors are with Princess Sumaya University for Technology, Jordan (e-mail: s.mehtap@psut.edu.jo, yazanjayyousi@hotmail.com, njoodgammoh@yahoo.com, ahmadalhaj601@gmail.com). improvements in their rights and standards of living, and governments in this region are being pressured to create more jobs and improve the welfare of their people. Arab societies still have the traditional viewpoint that women must be committed to their homes and children [14]-[18] and thus Arab women constitute only 25 percent of workers in the Arab world [19].

Jordan is a developing country that is faced with high levels of youth unemployment and a steady influx of refugees that are a heavy burden on its economy and infrastructure. Additionally, there is rising public anger over wide spread corruption, economic austerity measures and inadequate political reforms [19]. Jordan lacks natural resources and therefore, the country's main wealth lies in its human capital. Despite high literacy rates amongst women [20], [21], their participation in the workforce has been slow over the past 30 years, increasing from 12 percent in 1985 [22] to 16 percent today [23].

There is a growing body of research that tries to document the reasons for low workforce participation amongst women in the Middle East [8], [12]. Yet, there is a paucity of research that focuses on Jordan in particular [9]. Jordan has a special status amongst Arab countries in terms of high female literacy and tertiary education levels [8],[23]. Despite the high number of female university graduates, female workforce participation is low [24]. Therefore, there is a need to understand why Jordanian women refrain from taking part in the workforce. This exploratory study is loosely modeled on the work of [25], [26] and attempts to answer the following research questions from the perspective of non-working Jordanian women:

- What is the profile of the non-working woman in Jordan and how satisfied is she with staying at home?

- Do women perceive socio-cultural and economic-legal factors as barriers to participation in the workforce?

- Are there any significant differences in these perceptions according to certain demographic variables? (education level, age, marital status, family income and religion)

\section{LITERATURE REVIEW}

\section{A. Factors Affecting Labor Force Participation Demographic Variables}

Previous studies have highlighted certain demographic variables that can encourage or discourage women from working. One of these variables is education. When women are educated, they become open to new ideas, develop new skills and broaden the options they have available outside of the home [27]. Therefore, providing education and training for females helps them to be more active participants in the 
workforce, grants them economic freedom and allows them to support economic development [28], [29]. Unfortunately, research has also shown that advances in education do not always translate into better economic opportunities for women [21].

Different authors have looked at women's workforce participation according to different stages of her life cycle. Reference [30] found that in the early life stage, a woman's main focus was on three areas: taking care of their kids, domestic management and career development. Reference [31] found that most families believed that a woman should not work outside her home when she has children under school age, except if there is a financial need. Other studies have shown that a woman's career gains more importance in midlife [11], [32]-[34].

A majority of married women still have to bear the burden of home, family and childrearing with limited help from their spouses [10], [30]. Those who also have to work find that they are unable to balance full time work with motherhood and home life and prefer to opt out or look for part- time jobs [35]. Women account for the most unpaid work and when they are paid there is still a significant gender pay gap [10]. In developing countries, changes in the earning power of the patriarch affects a women's decision to join the labor market [9], [36]. Nowadays, due to changing lifestyle requirements and increasing expenses only one source of income to support the family isn't enough. Therefore, women are being encouraged to find jobs to support their families [25]. Spousal support in household chores and child care is important for women who would like to pursue their careers or make a contribution to the family income [37].

Religious beliefs can also affect a woman's choice to work. Christianity, does not differentiate between the genders when it comes to work life. However, in the case of marriage, the man is the head of the house, and the breadwinner [38]. In Islam, there are different views regarding women in work life. The traditional scholars stress that women should dedicate her life to her home and family and it is not preferable for her to work. On the other hand modern scholars emphasize the importance of a woman's role in economic life, state that she is required to wear the veil and indicate that the veil is not an obstacle to work [12].

\section{B. Women's Workforce Participation in the Arab World}

Women in the Arab world continue to face restrictions in political, economic and social spheres [39], [40].The Arabs are trying to maintain their roots, while forging new universal identities post Arab Spring. Arab women are calling for more emancipation, however, there are many social, culture, and environmental factors that still affect mostly negatively- women's participation in the labor force [41].

According to [6]-[8], certain socio-cultural factors have been pinpointed in studies across the MENA region that affect women's workforce participation. These have been cited as: limited mobility, lack of equal access to education, patriarchal dominance in society, religious restrictions, lack of spousal consent and a distinct separation of public and private life. On the other hand, the same authors have also drawn attention to economic and legal factors that can affect women's workforce participation. These are: discrimination between the genders, weak implementation of laws that protect women's rights, limited access to capital, finance and information and the gender pay gap.

Jordan is a collectivist, paternalistic, patriarchal and tribal society, where religion plays an important role in the governance of society. The socio-cultural structure of Jordanian society has a prominent role in determining the reason behind women's low participation in the workforce [39], [42]. For example, Jordanian textbooks still contain examples of gender based stereotypes. Many public schools are segregated because of cultural sensitivity towards the mixing of genders, which later goes on to affect men's and women's ability to deal with many situations at the workplace [21]. Although many females receive a university education, they are still encouraged to find a husband and start a family rather than focus on a career [43], [39]. According to [44], cultural constraints sometimes ban women from working in low prestige areas, jobs that require travel and contact with strangers, and jobs with long working hours. All these limitations help to lay the foundation for further gender inequality within the workplace.

Economic/legal factors in Jordan play a crucial role in defining the engagement of women in different kinds of professions. Because Jordan is an Islamic country, the laws are pre-dominantly based on Sharia, which gives men authority over women. For example, a woman must live with her husband and move with him if he needs to change residence and a woman must have her husband's permission if she wants to work. This ties her career life and work choice to her husband's decision and circumstances [21].

There are lots of gender issues in the labor market when it comes to the legal provisions and there is a discrepancy between application in the public and private sectors. Men earn nearly double that of women in the private sector and for this reason women prefer to work for the public sector which also has the advantage of fixed working hours [5]. Some regulations promote the concept of women's work as a secondary character and reduce the incentives for married women to work [21]. For example the Ministry of Labor allows women to work late hours only in certain occupations, otherwise it is forbidden. On the other hand, some laws in Jordan are in line with international standards and actually 'favor' females. Unfortunately, most women are unaware of those rights, or are unable to ask for them due to social pressure or fear [21].

\section{Methodology}

\section{A. Sample, Questionnaire and Data Collection}

The data used in this research was collected from 145 unemployed females living in Jordan. The questionnaire was taken from the work of [25] and [26] modified according to Jordanian society and professionally translated into Arabic. Both electronic and paper versions were produced. The questionnaire consisted of three parts. The first part is related to demographic factors and the following parts measure respondent's perceptions about certain socio- 
cultural/economic-legal factors that may affect women's participation in the labor force. A single 5-point Likert scale question was used to measure whether these women were satisfied with staying at home. The paper based questionnaires were distributed inside and outside of Amman in the public places and a snowball sampling technique was used to collect data from amongst family and acquaintances. Data was collected over a three week period and the total response rate was 92.3 percent. Data was coded and descriptive statistics, t-tests and one way ANOVA was conducted using SPSS.

\section{RESUlts}

\section{A. A Profile of Non-working Women in Jordan}

The majority of respondents were from Amman, Muslim, married with children, between the ages of 26 to 35, with an undergraduate degree, a family income of more than a thousand JDs, and no work experience. Those who did have work experience, indicated childbirth or marriage as the reasons for leaving work and this is in line with the literature on this subject [36]. Her main source of income is her husband, followed by her parents if she is not married. She spends on average of 4-6 hours a day on household chores, and does not have an active social life. If she was to work, it would be for reasons of self- actualization and preferably in the public sector. As has been stated before, Jordanian women prefer to work for the public sector due to better pay and working conditions [22] and it is also deemed to be more socially acceptable [23]. A majority of the respondents had university degrees and may feel that they have wasted their education and talent and therefore feel the need to work in order to achieve a higher potential. The respondents were generally not satisfied with staying at home $(\mathrm{m}=2.54)$.

\section{B. Perceptions of Socio-Cultural and Economic-Legal Barriers}

In general these women acknowledged that there were socio-economic factors deterring them from engaging in the work force. Except for education level and family income there were no significant differences in perceptions with respect to certain demographic factors. Respondents believe that religious beliefs and gender stereotypes should not be an obstacle to working and are against men being given preferential treatment for positions just because they are perceived to be the main bread winner in society. Yet on the other hand, most women believe that the man is responsible for taking care of the wife and all her financial matters, which is in line with report [39] on gender issues in Jordan and a contradiction to what most of these women have indicated before. Women believed that they would be able to cope with bullying and harassment within the workplace, even though most had never worked in their lives. Sometimes their perceptions did not reflect actual reality and the study found that many women were not really aware of the existence of women friendly labor laws.

\section{CONCLUSION AND RECOMMENDATIONS}

Despite the fact that female literacy rates in Jordan are the highest in the region, women are still far behind men in terms of employment [23]. The women participating in this study have perceived socio-cultural and economic-legal factors to be barriers to women's workforce participation. Engaging women in work life is imperative for the economic development and prosperity of Jordan. This study urges policy makers to improve work-related legislation and conditions for women, and to take measures that will eliminate discriminatory practices within the workplace [39]. Second, effective monitoring is needed to make sure that existing women-friendly laws such as those governing childcare facilities within companies are actually implemented. The government can help increase the number of females in workplaces by offering tax incentives to employers. The social roles that have been assigned to both genders as a result of dominant cultural and religious factors seem to be significant obstacles for the advancement of women in Jordanian society. This highlights a need to break down gender stereotypes and cultural taboos within society. This will only come about through further education and building awareness in all levels of society. Both men and women need to be committed to advance this critical agenda and to alleviate the status and economic participation of women in Jordan.

\section{REFERENCES}

[1] C. Lagarde, Dare the Difference, Finance and Development, International Monetary Fund, 2013.

[2] World Bank Group, World Development Report, Washington: Gender Equality and Development, 2011.

[3] S. Al-Botmeh, Policies to Improve Labour Movement's Participation in Public Policy, Palestine Economic Policy Research Institute, 2013.

[4] European Commission, Strategy for Equality between Women and Men 2010-2015, Luxembourg: Publications Office of the European Union, 2011.

[5] Department of Statistics (DoS), Women and Men in Jordan in Figures, Amman, Jordan, Department of Statistics, 2008.

[6] N. El Saadawi, On Women, Religion and Morals, Cairo: Al Arabiya for Publishing, 2006.

[7] N. F. Khoury and M. Moghadam, Gender and Development in the Arab World: Women's Economic Participation-Patterns and Policies, London: Zed Publication, 1995.

[8] C. Mcloughlin, Women's Economic Role in the Middle East and North Africa (MENA), Helpdesk Research Report, 2013.

[9] A. Al Kharouf and D. Weir, "Women and work in a Jordanian context: Beyond neo-patriarchy," Critical Perspectives on International Business, vol. 4, no. 2/3, pp. 307-319, 2008.

[10] F. Büchel and C. K. Spieß, Childcare Arrangements and Mothers Labor Market Participation in West and East Germany, Federal Ministry for Family Affairs, Senior Citizens, Women and Youth. Stuttgart: W.Kohlhammer, vol. 220, pp. 108-109, 2002.

[11] J. R. Gordon and K. S. Whelan-Berry, "Successful professional women in mid-life: How organizations can more effectively understand and respond to the challenge," Academy of Management Executive, vol. 12, no. 1, pp. 8-24, 1998.

[12] Y. Sidani, "Women, work, and Islam in Arab societies," Women in Management Review, vol. 20, no.7, pp. 498-512, 2005.

[13] S. Verick, Female Labor Force Participation in Developing Countries, IZA World of Labor, pp. 87-88, 2014.

[14] I. Abdalla, "Attitudes towards women in the Arabian Gulf region," Women in Management Review, vol. 11, pp. 29-39, 1996.

[15] R. Assaad, R. Hendy, and C. Yassine, Gender and the Jordanian Labor Market, Economic Research Forum Working Paper 701, 2012.

[16] A. El-Jardawi, "Problems of Kuwaiti and Arabian gulf working women," Zat-Elsalasil, 1996.

[17] S. El-Rahmony, Women in the Arab World: from Role Conflict to Effective Participation, Beirut: Al-Mustaqbal Al-Arabi (The Arab Future), Centre for Arab Unity Studies, 2002.

[18] A. Orabi, "Arab women: Tradition and modernity," Liberation of Arab Women, Arab Future Book Series, vol. 15, 1999. 
[19] World Bank Group. (2013). Opening Doors: Gender Equality and Development in the Middle East and North Africa. [Online]. Available:

https://openknowledge.worldbank.org/bitstream/handle/10986/12552 /751810PUB0EPI0020601300pening0doors.pdf?sequence $=1$

[20] V. Barcucci and N. Mryyan, Labour Market Transitions of Young Women and Men in Jordan, Youth Employment Programme Employment Policy Department, Work4Youth Publication Series no. 14, 2014.

[21] A. M. Majcher-Teleon and O. B. Slimène, "Women and work in Jordan: A case study of tourism and ICT sectors," European Training Foundation, 2009.

[22] Department of Statistics (DoS), Employment and Unemployment Survey, EUS, Amman, Jordan, Department of Statistics, 2008a.

[23] World Bank Group. (2014). Women in Jordan - Limited Economic Participation and Continued Inequality. [Online]. Available: http://www.worldbank.org/en/news/feature/2014/04/17/women-injordan---limited-economic-participation-and-continued-inequality

[24] R. Assaad and R. Hendy, On the Two-Way Relation between Marriage and Work: Evidence from Egypt and Jordan, Economic Research Forum 19th Annual Conference, Kuwait, 2012.

[25] S. Al-Dehailan, "The participation of women in Saudi Arabia's economy: Obstacles and prospects," M.S. thesis, Durham Univ., Durham, UK, 2007.

[26] A. Al-Dhafiri, "Women, labor force participation, and equality: A study of educated women in Kuwait," M.S thesis, Ohio State University, Ohio, USA, 1987.

[27] A. Bullough, K. Kroeck, W. Newburry, S. K. Kundu, and K. B. Lowe, "Women's political leadership participation around the world: An institutional analysis, " The Leadership Quarterly, vol. 23, no. 3, pp. 398-411, 2012.

[28] E. Boserup, Woman's Role in Economic Development, Brookfield, Vermont: Gower, 1986

[29] J. A. Lincove, "Growth, girls education, and female labor: A longitudinal analysis," The Journal of Developing Areas, vol. 41, no. 2, pp. 45-66, 2008.

[30] J. R. Gordon and K. S. Whelan-Berry, "It takes two to tango: An empirical study of perceived spousal/partner support for working women," Women in Management Review, vol. 19, no. 5 pp. 260-273, 2004.

[31] C. Davey and M. Davidson, "Policies and practices to encourage women returners," Women in Management Review, vol. 9, no. 7, pp.4-14, 1994.

[32] C. K. Gersick, "High-achieving women at mid-life: An exploratory study," Journal of Management Inquiry, vol. 11, no. 2, pp. 104-127, 2002.

[33] J. R. Gordon, J. E. Beatty, and K. S. Whelan-Berry, "The mid-life transition of professional women with children," Women in Management Review, vol. 17, no. 7, pp. 328-341, 2002.

[34] J. D. Reid and S. L. Willis, Middle Age: New Thoughts, New Directions, San Diego, CA: Academic Press, 1999.

[35] P. Dickens, "Human services as service industries, "The Service Industry Journal, vol. 16, no. 1, pp. 82-91, 1996.

[36] G. Motraza, Female Labour Force Participation in Developed and Developing Countries, Nova Scotia, Canada: Dalhousie University Halifax, 2005.

[37] M. H. Benin and J. Agostinelli, "Husbands' and wives' satisfaction with the division of labor," Journal of Marriage and the Family, vol. 50, pp. 349-361, 1988.

[38] G. Kuykendall, Biblical Marriage Study, Officers' Christian Fellowship of the U.S.A, 2008.

[39] H. Hakki and S. Somach, Gender Analysis and Assessment, USAID/JORDAN, 2012.

[40] M. M. Mostafa, "Attitudes towards women who work in Egypt," Women in Management Review, vol. 18, no. 5, pp. 252-66, 2003.
[41] I. Boullata, Trends and Issues in Contemporary Arab Thought. Albany, NY.: State University of New York Press, 1990.

[42] R. Hendy, Investigating Female Labor Force Participation: A Dynamic Analysis for Egypt and Jordan, The Social-Economic Situation of Middle East Youth on the Eve of the Arab Spring Conference, Beirut. Workshop Discussion Paper, 2012.

[43] M. Amer, The School-to-Work Transition of Jordanian Youth. Economic Research Forum, Working Paper 686, 2012.

[44] A. E. Kharouf, Factors Influencing the Employment of Women from the View of Employed and Non-Employed Women and Managers in Amman City, Unifem, 2000.

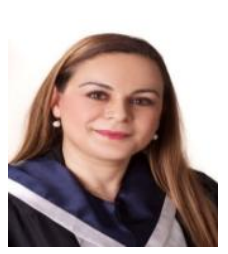

Salime Mehtap was born in Australia in 1971 and holds an MBA degree and a $\mathrm{PhD}$ in organisational behaviour. She is currently teaching entrepreneurship and management classes at both the undergraduate and postgraduate levels in Amman, Jordan. She was previously teaching in Cyprus and also held administrative positions such as the director of the Office of International Affairs and Head of the International Student Center. Dr. Mehtap has supervised post graduate theses and published in international peer reviewed journals. Her research interests include female and minority entrepreneurship, service quality, expatriation and cross cultural adjustment. She is a certified trainer in 'soft skills' development and cross border mobility and enjoys discovering different cultures.

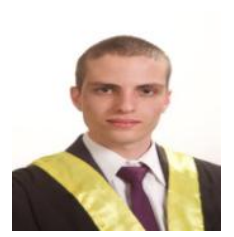

Yazan Jayyousi was born in Amman, Jordan in 1992. Yazan graduated with honours from the Department of Business Administration at Princess Sumaya University for Technology, Jordan. He speaks Arabic and English and wrote for 'MyKali' which is an online magazine that tackles issues such as women's rights, personal politics, freedom of speech and media related topics in Jordan and the Arab Region. Yazan traveled to Taiwan as a part of a cultural exchange program and was also an exchange student at Cardiff Metropolitan University, UK for ten months. He has certification in the 'methodology of thinking' and in 'sustainability'. His main research interest is gender studies.

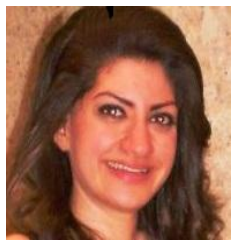

Njood Gammoh was born in Amman, Jordan in 1993. She is a graduate of Business Administration from Princess Sumaya University for Technology, Jordan. She is aiming to continue her education by completing her postgraduate degree in human resources. Njood is a native speaker of Arabic and fluent in English. Her research interests include women in management and women's workforce participation.

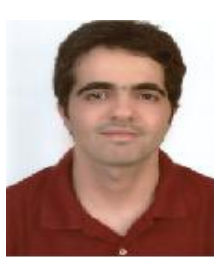

Ahmad Al Haj was born in Amman, Jordan in 1992 and has a bachelor's degree in business administration. Ahmad speaks Arabic, English and Japanese. In 2014, he represented Jordan in the Japan Middle East Student Conference which was held in Tokyo and was able to present Jordan's perspective on the Syrian refugees in Jordan, and their socio-economic burden on the country. Ahmad's research interests include the dynamics of Asian economies and Japanese culture. 